Indexaciones: Repositorio de Revistas UCR, DIALNET, Latindex, REDALYC Directorio y recolector de recursos digitales del Ministerio de Cultura de España, Directory of Open Access Journals. Diálogos Revista Electrónica de Historia ISSN 1409-469X. Número especial 2008. Dirección web: http://historia.fcs.ucr.ac.cr/dialogos.htm

\section{Centroamérica en la estrategia diplomática mexicana: entre la política y la difusión cultural (1920- 1932)}

\section{María del Carmen Díaz Vázquez}

Maestra en Estudios Latinoamericanos por la Universidad Autónoma de México y doctora en Historia por la Universidad de Costa Rica. Profesorainvestigadora a la Universidad Autónoma de la Ciudad de México.coijuxmex@yahoo.com.mx 


\section{Introducción}

En los años veinte del siglo pasado, Centroamérica fue considerada como una región estratégica dentro de la política exterior mexicana. Por esta razón, se diseñó un plan especial para propiciar el acercamiento diplomático. Este afán estaba vinculado al interés por ganar adeptos para hacer frente a las hostilidades de los Estados Unidos a raíz del artículo 27. Éste había sido incluido en la Constitución de 1917 y limitaba los intereses extranjeros en el país, desafiando así los poderes imperiales. Por primera vez, en la historia contemporánea de América Latina, un ordenamiento constitucional cuestionaba el derecho de propiedad de extranjeros sobre explotaciones mineras, yacimientos petrolíferos y explotaciones agrícolas-ganaderas. Por esto, el conflicto alcanzó considerables proporciones cuando aquellos poderes se negaron a aceptar las leyes fundamentales de México.

Dado el contexto anterior, si bien México no pretendía exportar su revolución, en el sentido de propiciar que se repitiera su experiencia en la región centroamericana, sí pretendió convertirse en ejemplo y especie de $\square$ hermano mayor $\square$ que podía guiar a los países centroamericanos en la resolución de sus problemas de construcción nacional. En este sentido, pretendió ejercer hegemonía sobre la región centroamericana, considerada por algunos políticos e intelectuales como área de influencia natural de México - a pesar del fuerte control de los Estados Unidosdebido a su cercanía geográfica y a los nexos existentes desde la época colonial.

En el centro de la política de difusión y acercamiento cultural con los países latinoamericanos, los intelectuales mexicanos y centroamericanos desempeñaron un papel determinante como difusores y ejecutores de políticas. En este trabajo nos referiremos a José Vasconcelos se encargó del diseño de las políticas culturales dirigidas hacia la región y a Juan de Dios Bojórquez, el ejecutor de dichas políticas en la región

Desde el ámbito oficial, los mecanismos de propaganda abarcaron puntos centrales de la difusión cultural a través de reparto de libros, creación de una agencia de noticias, otorgamiento de becas a estudiantes, entre otros. Esto fue parte de una estrategia general vinculada, además, al interés político y económico.

\section{José Vasconcelos y la política de difusión cultural}

La simpatía que muchos intelectuales de la época expresaron por Vasconcelos y el México posrevolucionario estuvo relacionado con la efervescencia, en el ámbito intelectual, de la búsqueda de la originalidad hispanoamericana. Por ejemplo, surgieron nuevos pensadores 
antipositivistas como Antonio Caso (junto con José Vasconcelos) en México, Alejandro Korn, Manuel Ugarte y José Ingenieros en Argentina, Manuel González Prada en el Perú o José Enrique Rodó en Uruguay, sin dejar de lado la influencia que tuvieron filósofos españoles como Miguel de Unamuno o José Ortega y Gasset.

Las ideas arielistas y antiimperialistas estuvieron presentes en la Revolución Mexicana; el capital extranjero unido a la pequeña oligarquía nacional impedía, según los revolucionarios, que se realizara la voluntad del pueblo.

Vasconcelos, como rector de la Universidad Nacional, inició su tarea educativa y promovió la idea de volver a instalar la Secretaría de Educación Pública. La nueva secretaría se distinguía considerablemente de la porfirista. Ahora, pretendía ser un organismo que tuviera jurisdicción sobre todo el país; es decir, significaba la federalización de la enseñanza. El presidente Obregón introdujo la iniciativa al Congreso y la Secretaría fue creada el 28 de septiembre de 1921. El 10 de octubre de ese mismo año, nombró a Vasconcelos secretario de educación. ${ }^{1}$ Entre sus prioridades se encontraban los siguientes: educación indígena para asimilar la población marginal; educación rural para mejorar el nivel de vida del campo mexicano y educación técnica para elevar el de las ciudades; creación de bibliotecas; publicación de libros populares; popularización de la cultura, entre otras. ${ }^{2}$

En 1922, Obregón concedió a la SEP un presupuesto cinco veces más en pesos pércapita que Porfirio Díaz en 1900-1901 y dos veces, más o menos, que Madero en 1912. ${ }^{3}$ Este gran presupuesto era condición necesaria para la nueva imagen que se quería construir del país a partir de la educación, la cultura y la democracia. Ésta sería proyectada por Vasconcelos desde su puesto oficial hasta el término de su cargo.

En 1924, Vasconcelos decía que la Revolución Mexicana se había definido a sí misma durante el régimen de Obregón por sus tres fines principales: fragmentar los latifundios, organizar la mano de obra y educar a las masas. Agregaba que la revolución estaba todavía muy viva y había que darle forma mediante el programa educativo. Para él ser revolucionario era sinónimo de ser maestro. "La revolución anda ahora en busca de sabios" ${ }^{4}$ fue su llamado a los estudiantes

1 Cfr. Josefina Vázquez de Knauth, Nacionalismo y educación en México ( México: COLMEX, 1979), p. 139.

2 Ibid.

3 Véase, John Skirus, José Vasconcelos y la cruzada de 1929 (México: Siglo XXI).

4 José Vasconcelos, “Discursos en la Universidad, con motivo de la posesión del cargo de rector”, citado por Ibíd. 
universitarios en junio de 1920, para que participaran en la campaña contra el analfabetismo. A cambio, se les concedieron diplomas por enseñanza voluntaria.

Desde un principio, la Secretaría de Educación Pública proyectó su política de acción en muchas direcciones, entre éstas el ámbito obrero. Al respecto, Vasconcelos sostenía que sólo el contacto íntimo entre obreros e intelectuales podría producir el renacimiento espiritual deseado. Mantuvo el contacto entre ambos sectores fundando escuelas vocacionales y pronunciando discursos en eventos culturales donde asistían obreros.

Un aspecto central, inspirador de la obra de Vasconcelos, fue la idea de que México fuera un centro cultural para toda la América Latina. La Secretaría de Educación se hizo famosa en los países de habla hispana gracias a sus publicaciones, ampliamente distribuidas: ediciones de clásicos, boletines de la universidad con discursos de Vasconcelos y El Maestro-Revista Nacional.

Para llevar a cabo ese objetivo, la Secretaría de Educación empleaba como activistas culturales a artistas e intelectuales de renombre, en el ámbito mexicano e hispanoamericano. Por ejemplo, Diego Rivera con sus murales proyectaba los ideales revolucionarios y sus ideas marxistas; en la Escuela de Verano de la Universidad Nacional de México a donde asistían extranjeros, el dominicano Pedro Henríquez Ureña enseñaba literatura mexicana y Vicente Lombardo Toledano discurría sobre la historia de México y la revolución de 1910. Vasconcelos nombró a éste director de la Escuela Nacional Preparatoria. Raúl Haya dela Torre, refugiado político del régimen de Leguía en el Perú, daba conferencias sobre historia de Iberoamérica y la escritora chilena Gabriela Mistral, invitada por Vasconcelos, escribía Lecturas para mujeres. Además, fue maestra de niños campesinos, como parte del primer grupo de maestros misioneros, que recorrían las escuelas del campo introduciendo reformas. ${ }^{5}$ También intelectuales centroamericanos como Rafael Heliodoro Valle, participaron activamente en el proyecto educativo vasconceliano.

Una teoría continental de la Revolución Mexicana -en la forma de la homogeneidad racial en la América Latina- se sintetizaba en la llamada raza cósmica, que sería el siguiente capítulo de la historia universal. Esta idea fue expresada y difundida por José Vasconcelos. Omitiendo los términos Latinoamérica, Iberoamérica, Hispanoamérica, Indoamérica o Panamérica, se refería a cierto tipo de “cosmopolitismo”, en el cual la América Indoibérica era el asiento de una nueva cultura mundial o "cósmica”. En la práctica, la raza cósmica de Vasconcelos, significó el

$5 \quad$ Skirus, 19. 
reconocimiento del mestizaje y su uso como instrumento de homogeneización nacional. ${ }^{6}$

Las ideas de Vaconcelos tuvieron un impacto considerable en Centroamérica y en el resto de América Latina, convirtiéndose en la figura continentalista que, posiblemente, destacó más en las publicaciones de la intelectualidad de la región en los años veinte. Con relación a sus ideas continentalistas escribía en 1923:

Yo soy de los que creen que el sentimiento de Patria es demasiado pequeño para los corazones libres y pongo mi fe en el internacionalismo sincero y total [...] Creo que la nacionalidad es una forma caduca [...] Veo la bandera iberoamericana flotando una misma en el Brasil y en México."”

En los años veinte, Vasconcelos ocupó las primeras planas en los principales diarios de Costa Rica y de Guatemala. Es éstas se le rindieron homenajes, que despertaron el interés de los sectores medios. ${ }^{8}$ Joaquín García Monge en Repertorio Americano, semanario que reunía a los pensadores latinoamericanos más destacados del momento, dedicó gran espacio a Vasconcelos y sus disertaciones filosóficas.

En calidad de embajador cultural tuvo una presencia fuerte y prestigiada, pero cuando pretendió difundir su causa política a través de ataques a la revolución y sus gobernantes, la recepción oficial tendió a variar, esto a partir de la década de los treinta.

En el caso guatemalteco, en las revistas culturales y estudiantiles, el pensamiento vasconceliano fue retomado con entusiasmo. En el diario El Imparcial, considerado como un centro donde confluían los mexicanistas, se dedicaron espacios importantes para mostrar la grandeza de México y la labor realizada por el secretario de educación. Se puso énfasis en las buenas relaciones de este país y Guatemala, a través de la política de acercamiento cultural impulsada por éste. Al respecto se citaban sus palabras: "México desea estrechar más las relaciones con las repúblicas hermanas del sur; y espero que mi misión contribuya a convertir en realidad sus deseos". ${ }^{9}$

6 Ibíd., 213.

7 Ibíd., 101.

8 La Tribuna (Costa Rica), "Homenaje del Liceo de Costa Rica al Licenciado Vasconcelos y a "Miss Costa Rica”, 6 de abril de 1930, 1.

$9 \quad$ El imparcial (Guatemala), “El licenciado José Vasconcelos. Rector de la Universidad Nacional de 
La política de difusión cultural, propagada desde la Secretaría de Educación Pública, recibía elogios, al igual que la labor emprendida por la Universidad Nacional. Esa política se concretizó, como ya dijimos, con la distribución gratuita de diversas publicaciones en el ámbito centroamericano, específicamente guatemalteco. Ahí se consideraba que en México se había emprendido una intensa labor de regeneración cultural, dirigida por Vasconcelos. También se elogiaba la publicación de obras de literatura clásica, que se repartían para "lograr la depuración del gusto popular tantas veces descarriado por falsas corrientes estéticas". ${ }^{10} \mathrm{Se}$ comentaba:

Hasta nosotros han llegado, como el resto de Centro América, arrastrado por una fuerte corriente de simpatía, en beneficio de tales intentos. Ya se han fundado en el país algunas bibliotecas bajo los auspicios de la Patria de Juárez, los existentes aumentaron por el momento su riqueza de volúmenes, y muchos de nuestros intelectuales han sido obsequiados con un lote de valiosos ejemplares. ${ }^{11}$

El reparto de libros también se dirigió a bibliotecas del interior de Guatemala y a las sedes de la Universidad Popular, institución creada en los años veinte a partir de una idea difundida por Vasconcelos. Sobre este tema profundizaremos más adelante.

Los editorialistas de El Imparcial agregaban que en México se poseía la locura del libro porque éste se regalaba, se creaban bibliotecas por todas partes, difundiendo así su exaltación ideológica. ${ }^{12}$ En contraparte se criticaban las trabas a la entrada de los paquetes de libros obsequiados por México.

Entre las publicaciones que se distribuyeron en Guatemala se encontraban El maestro y El libro y el pueblo. Respecto al primero, El imparcial señalaba que se imprimía y repartía un número considerable (cien mil ejemplares) que se distribuían gratuitamente. Algunos de ellos fueron enviados como obsequio a los escritores. Al respecto, el editorialista manifestaba: "somos vecinos de una gran nación de nuestra raza y debemos cultivar su amistad”. ${ }^{13}$

El libro y el pueblo recibió atención especial, se le consideraba una publicación importante, México y ardiente panamericanista va a Brasil y Argentina en Misión de fraternidad”, 3 de agosto de 1922, 1. 10 El imparcial, "Laudable labor de la Secretaría de Educación Pública de México", 13 de noviembre de 1922, 1.

11 Ibíd.

12 El imparcial, "Hemiplejia de la educación. El libro caro", 24 de mayo de 1923, 3.

13 El Imparcial, 26 de agosto de 1922, 3. 
porque mostraba la fase en que se encontraba el movimiento educativo de los mexicanos. Además de los datos bibliográficos que proporcionaba la revista, difundía "una idea germinal, elevada... la idea de la América libre y activa de su papel en la gran obra de rectificar y elevar la civilización.” ${ }^{14}$ Así, México, revelaba en sus revistas, en sus libros, en sus boletines, una lucha intensa por las ideas y una revolución tan vasta, "como acaso no existe hoy en otro pueblo del mundo". ${ }^{15}$

En 1925, la SEP de México obsequió 175 volúmenes de libros para formar la base de las cinco bibliotecas infantiles que instalaría la Sociedad Protectora de la Niñez. El donativo fue gestionado por José Guillermo Salazar, guatemalteco residente en la capital mexicana. ${ }^{16}$

Las campañas educativas impulsadas por la SEP en México fueron conocidas en Centroamérica a partir de las publicaciones mencionadas, convirtiéndose en ejemplo a seguir y consideradas como un estímulo de acción y esperanza. Así, Vasconcelos fue colocado en el centro de los "nuevos hombres de México", ${ }^{17}$ por su labor en el ámbito educativo. La política seguida en su país fue considerada como formidable, trascendiendo así sus fronteras y convirtiéndose en un modelo a seguir ya sea para el gobierno, la prensa y el campo de la acción ciudadana.

Se retomó la idea de Vasconcelos referida a la educación, como impulso necesario, para la resolución de los diversos problemas de las naciones latinoamericanas. Ahondando en el asunto, el periodista y poeta nicaragüense Juan Ramón Avilés señalaba la importancia que México adquirió como difusor de nuevas corrientes de pensamiento y de transformación:

De México nos ha llegado, necesario es no olvidarlo, todas las grandes corrientes que han conmovido la historia centroamericana... Y así como nuestra independencia y nuestro liberalismo han tenido por origen los de México, sea por la vecindad o porque como hermanos estos pueblos han sentido casi a un mismo tiempo la necesidad de las grandes transformaciones, el caso es de que de allá nos llegan ejemplares de verdadero liberalismo, en la actuación y en las palabras de sus gobernantes, e igualmente estamos recibiendo la influencia del movimiento socialista que ya está repercutiendo entre nosotros.

Y ese influjo espiritual de México en Centroamérica se nota ya en las universidades, en

$14 \quad$ El Imparcial, 5 de mayo de 1923, 3.

15 Ibíd.

16 El imparcial, "Bibliotecas de la Casa del Niño. Valioso donativo de la Secretaría de Educación Pública de México”, 3 de junio de 1925, 1.

17 Juan Ramón Avilés, “Los nuevos hombres de México”, El imparcial, Guatemala, 24 de mayo de 1923, 4. 
las bibliotecas y en los libros que...vienen a entregarnos la buena nueva que en México hay un hombre que está organizando a su país para que el espíritu sea el que en la cultura hable para nuestra raza. ${ }^{18}$

La labor desempeñada por Vasconcelos era comparada con la realizada por Sarmiento en la Argentina del siglo XIX. El afán integrador del proyecto educativo del mexicano fue aceptado positivamente (por lo menos en el discurso), por una parte de la intelectualidad guatemalteca de esos años. ${ }^{19}$ Fue considerado un apóstol, un ejemplo a seguir por los ministros de Centroamérica, a quienes se les cuestionaba su desempeño. ${ }^{20}$

La labor de Vasconcelos no sólo recibió comentarios de intelectuales latinoamericanos, sino también de norteamericanos y de otras nacionalidades. El Imparcial reprodujo los comentarios vertidos por Mr. Gruening, tomados de la versión publicada en Repertorio Americano. Para Gruening, Vasconcelos formaba parte de los seis hombres que estaban desempeñando papeles primordiales, no sólo en la reconstrucción de su país, sino en la modelación del futuro de una raza en la mitad del Hemisferio. También enfatizaba el significado adquirido por la educación para sacar al pueblo mexicano de la miseria, de la degradación y de la ignorancia en que había estado “enlodado" por siglos. ${ }^{21}$

Desde la perspectiva de Vasconcelos y de los intelectuales centroamericanos, el acercamiento entre Guatemala y México parecía afianzarse a partir de la política cultural puesta en marcha por los diplomáticos y activistas. Por ejemplo, la llegada de estudiantes centroamericanos a escuelas mexicanas fortalecía la comprensión mutua. Los intelectuales señalaban que la influencia mexicana en Centroamérica seguía un camino ascendente desde la época colonial. Sin embargo, si esta influencia no se había concretado provechosamente no era culpa de los pueblos, sino de los gobiernos. Así la intervención de José Vasconcelos y Antonio Caso fue determinante para reorientar la situación. ${ }^{22}$

\section{Centroamérica en la visión geopolítica de Vasconcelos}

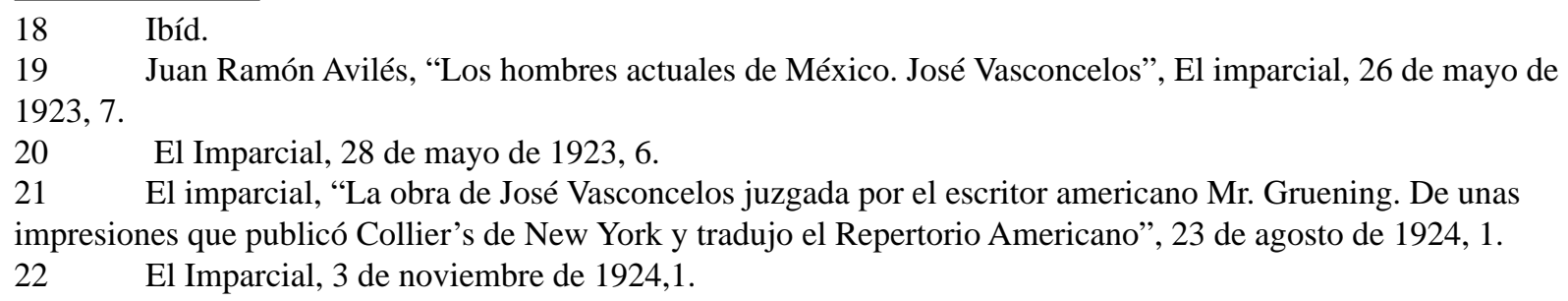


En torno a las relaciones exteriores de México, Vasconcelos concedía un significado especial a Guatemala. Destaquemos los puntos centrales de esta concepción a partir del documento "Unas palabras sobre Guatemala” (1924) ${ }^{23}$. En primer término, apoyaba la anexión de Belice a ese país, porque la grandeza de éste era tan importante para sus fines. Vasconcelos dedicó varias páginas de La antorcha al país centroamericano con la finalidad de romper la indiferencia que siempre había existido. Esta se traducía en el desconocimiento de su historia, de sus hombres y paisajes:

No logramos comprender que Guatemala es el más importante de todos nuestros afectos internacionales, y el punto de toque de nuestras relaciones con el resto del mundo. Es ésta una afirmación elemental. Si no consideramos a Guatemala, que es de nuestra misma sangre y más pequeña que nosotros, ¿ cómo vamos a pedir y esperar que a nosotros nos consideren los Estados Unidos que son mucho más grandes que nosotros y en cierto modo nos son extraños? ${ }^{24}$

A partir de la confrontación con Estados Unidos, Vasconcelos justificó la trascendencia que tenían para México Guatemala, Centroamérica y Sudamérica, es decir, Iberoamérica. Para el filósofo, si el acercamiento con Guatemala no se concretaba, el iberoamericanismo mexicano resultaría falso, porque sería cuestionado su apego a Argentina y a Brasil, más distantes geográfica y afectivamente:

Por lo que hagamos con Guatemala seremos juzgados en los países del Sur. Si nuestra amistad con Centro América no es desinteresada y leal, los sudamericanos jamás podrán tener confianza en nosotros. Guatemala es asimismo la clave de nuestra actitud con los demás países de Centro América. Que jamás vuelvan los días odiosos en que se juzgaba muy hábil política estar halagando a El Salvador, pero con el objeto de preparar amenazas combinadas contra Guatemala. Esto es tan infame que da vergüenza recordarlo. Sin embargo lo hicimos hace muchos años. Madero rectificó estas torpezas y la revolución tiene el mérito de haber continuado la nueva política, inaugurada por Madero, de hacer del

23 José Vasconcelos y las relaciones Mexicano-guatemaltecas (Guatemala: Editorial del Ejército. Guatemala, 1964). Reedición de Unas palabras sobre Guatemala. Por José Vasconcelos, Editoriales del Seminario "La Antorcha”, octubre y noviembre de 1924. Tomado de Anales de la sociedad de Geografía e Historia, Tomo I, 30 de junio de 1925.

24 Ibíd. 
Ministro de Guatemala, el convidado más próximo de todas nuestras fiestas. ${ }^{25}$ (Cursiva nuestra)

De acuerdo con el pensador el acercamiento, no bastaba con el simple intercambio de notas diplomáticas y atenciones. Esperaba la llegada de un presidente audaz que clausurara las aduanas de la frontera con Guatemala, desistiera de nombrar recaudadores y fiscales para no cobrar los derechos, dejando los caminos para el libre tránsito, sin pasaporte, adelantándose a lo que sucedería en el mundo. Si Guatemala no correspondía otorgando iguales franquicias, no importaba porque el beneficio moral y económico de abolir una frontera era inmenso. Señalaba, además, que su plan no era de predomino, de ventaja del más fuerte y mucho menos de interés en una posible integración guatemalteca a la federación, porque "queremos a Guatemala independiente, a Guatemala libre; más aún, queremos que en el Sur se funde un nuevo Estado, el Estado de Centro América, mientras más poderoso sea, más admirable. Tal debe ser la prueba plena de nuestra lealtad."26

La disertación vasconceliana que hemos comentado, tuvo una recepción importante en Guatemala. En años posteriores se siguieron rindiendo homenajes a Vasconcelos por su interés en el acercamiento con Guatemala. Uno de los puntos que más elogio mereció fue el referido a la pertenencia de Belice, asunto en el cual dicho país necesitaba apoyo.

En un discurso pronunciado por el guatemalteco Bernardo Alvarado Tello, con motivo de un aniversario más de la Independencia (1925), se refería a México como una de las dos democracias del norte, la otra era Estados Unidos, que junto con Argentina, Uruguay y Chile, formaban la vanguardia del continente, porque -decía- se habían "constituido en naciones grandes, por sus leyes sólidas, su patriotismo y sus inagotables riquezas naturales”. ${ }^{27}$

El programa vasconceliano de los años veinte para Guatemala y Centroamérica generó las simpatías esperadas, sobre todo, en el ámbito intelectual y estudiantil. Sin embargo, en los años siguientes la diplomacia mexicana no le dio continuidad.

\footnotetext{
25 Ibíd.

26 Ibíd.

27 Anexo. "Discurso oficial pronunciado por el Licenciado Bernardo Alvarado Tello en la conmemoración del CIV Aniversario de la Independencia Nacional ante el gobierno de la República, Cuerpo Diplomático, Municipalidades, distintas Corporaciones y vecinos de la Capital”, Guatemala, 1925. Sous série CentreAmérique. Carton 2, 1924-1927, Archivo del Ministerio de Relaciones Exteriores de Francia (AMAEF).
} 


\section{El reparto de libros, la radio y otros mecanismos de propaganda}

Como dijimos México articuló un plan de acercamiento y difusión positiva de su imagen en los países centroamericanos, a fin de contraponer la campaña de desprestigio emprendida por Estados Unidos.

Por eso se pusieron en marcha una serie estrategias que combinaron lo cultural con lo político. Así, para 1923, en un mensaje vertido en la apertura de sesiones ordinarias, dirigido por el presidente de El Salvador, Jorge Meléndez, mencionaba las becas que fueron otorgadas por el gobierno mexicano para que jóvenes salvadoreños pudieran continuar con sus estudios, dado que su país no contaba con la infraestructura necesaria, por ejemplo, para fundar un conservatorio de música, creía pertinente apoyar los esfuerzos individuales aceptando las becas que "el gobierno azteca” cedía. El apoyo no sólo se brindó para incentivar el desarrollo artístico, sino también el científico. De esta manera los becados tendrían acceso a Escuela Nacional de Industrias Químicas, a la Escuela Práctica de Ingenieros Mecánicos y a la Escuela de Medicina y Jurisprudencia. ${ }^{28}$

Otra medida tomada por el gobierno mexicano fue el obsequio de antenas inalámbricas a El Salvador (en el gobierno de Carranza), posteriormente a Costa Rica y Guatemala. Estas acciones eran justificadas por interés de acercamiento y apoyo desinteresado, aunque existían ciertas sospechas del diplomático francés, Paul Serré, quien señalaba que el representante mexicano en Costa Rica, en 1922, Ruiz, había confesado que México trabajaba activamente con las repúblicas centroamericanas en la formación de un bloque político compacto, opuesto a la potencia americana del Norte. Por eso creía necesario lo siguiente: instalar potentes estaciones telegráficas sin hilo; convertirse en propietario de los grandes periódicos de las capitales del Istmo; organizar, entre otras cosas, las líneas centroamericanas de vapor y atraer a México a estudiantes centroamericanos. ${ }^{29}$

Como se evidencia, la política mexicana se centró en la difusión de ideas, en el control del transporte comercial y la formación de cuadros destinados a propagar su imagen. Abarcando así, todos los ámbitos posibles para obtener resultados eficaces. Así sucedió.

El enviado francés, citado anteriormente, finalizaba su comentario diciendo que los diarios de San José, escribían que moralmente Centroamérica era una parcela de la Gran República de México, “tan viril, tan noble, tan querida "por los pueblos del mundo”, ${ }^{30}$ México pretendía

28 Sous série Centre-Amérique. Carton 1, 1918-1924, AMAEF.

29 Sous série Centre-Amérique. Carton 7, 1920-1928. San José, 18 de febrero, 1922, AMAEF.

30 Sous série Centre-Amérique. Carton 7, 1920-1928. San José, 18 de febrero, 1922, AMAEF. 
ser "una mano amiga de todos los pueblos del continente", pero se proponía nada menos que sustituir la hegemonía de los Estados Unidos sobre las repúblicas del Istmo y formar un bloque indio-latino, bajo su dirección. ${ }^{31}$

En 1925, se inauguraron en Guatemala las torres del equipo inalámbrico, obsequiado por México. El Imparcial citaba el discurso pronunciado por Cravioto, ministro mexicano en dicho país en el que decía: "México cumple ahora, con júbilo, uno de los postulados más eficientes de su política internacional: el de real cooperación con los pueblos hermanos, en ayuda colectiva y en beneficio de la humanidad". ${ }^{32}$ Señalaba que la estación obsequiada era la más poderosa que existía en casi toda América Latina. La estación estaba dotada de los últimos adelantos y capacidades que no existían ni en México. La Telefunken de Berlín fue la encargada de traer todos los receptores adecuados, mostrando el peso de la colonia alemana en ese país y su rivalidad con los Estados Unidos a raíz de la primera guerra mundial.

El asunto de las antenas inalámbricas y el servicio de radio, nos muestra cómo México pretendió hacer contrapeso a la influencia norteamericana en Centroamérica. La United Fruit Company había instalado el servicio inalámbrico en Puerto Barrios para su servicio particular y para el gobierno guatemalteco. Ante esta situación, los mexicanos, con la pretensión de estrechar relaciones, decidieron donar la estación de servicio inalámbrico para las ciudades de Guatemala, Quetzaltenango y San José. Esta funcionaría con o sin apoyo económico del gobierno guatemalteco. Los planes del gobierno mexicano iban más lejos que lo hecho por la empresa bananera. Su objetivo era establecer una red radiotelegráfica en Centroamérica dependiente de las estaciones federales para su comunicación internacional..$^{33}$

El control de los medios de comunicación, se fortaleció con otro de los mecanismos ideado por Vasconcelos para atraer la simpatía de los centroamericanos, en especial de los intelectuales y estudiantes: la distribución de libros. Esta política estaba enmarcada en el proyecto de difusión cultural posterior a la Revolución, al interior y fuera de país. En el informe presidencial rendido en 1923, Obregón señalaba la importancia concedida a la educación a través de la instalación de bibliotecas públicas, bibliotecas obreras, escolares, además de bibliotecas ambulantes y una circulante (en total 671 bibliotecas con 64, 520 volúmenes). Un espacio particular se otorgó 31 Sous série Centre-Amérique. Carton 2, 1924-1927, Ayme-Martin, Ministro Plenipotenciario de Francia en Centroamérica, Guatemala, 20 de enero, 1926, AMAEF.

$32 \quad$ El Imparcial, 8 de mayo de 1925, 1-2.

33 Telegramas cifrados y recortes de periódicos, Legajo 9, exp. 1, enero 1923- julio 1928, Archivo Histórico de la Secretaría de Relaciones Exteriores de México (AHSREM). 
a los libros repartidos en el extranjero, de los cuales varios ejemplares se distribuyeron en Guatemala. En dicho informe agregaba que en donaciones a bibliotecas se habían empleado 96,000 volúmenes que, unidos a los anteriores y a los repartidos en el extranjero, hacían un total de 102, 779 volúmenes. ${ }^{34}$

La difusión de la cultura, a partir del reparto de libros, estaba vinculada con la política interior llevada dirigida por Vasconcelos. Recordemos su afán por llevar la cultura a los lugares más apartados del país, donde el analfabetismo dominaba. La contradicción era evidente, pero exitosa desde la óptica exterior. Los diplomáticos franceses, existía un verdadero entusiasmo por elevar a los habitantes a un grado de cultura lo más alto posible, particularmente de las “clases inferiores".

Para los países centroamericanos México era un país ejemplar, especialmente en el ámbito educativo. En 1923, la Secretaría de Educación Pública de México nombró una comisión técnica que se encargaría de recibir a delegados de Honduras, Guatemala y El Salvador, comisionados por sus países con el objeto de estudiar los sistemas educacionales mexicanos e implementarlos en sus naciones. ${ }^{35}$ Este tipo de solicitudes no se limitó a la década de los veinte; para 1938, el Colegio Superior de Señoritas de San José, Costa Rica, por conducto de la legación mexicana en ese país, solicitaba datos sobre la enseñanza secundaria, la solicitud fue canalizada a la Comisión Mexicana de Cooperación Intelectual. ${ }^{36}$

Otra de las estrategias de México, para mantener su presencia en Centroamérica, se apoyó en las delegaciones comerciales y artísticas que recorrieron la región y otros países de América Latina.

A mediados de 1920, una delegación comercial mexicana llegó a Costa Rica. El Diario de Costa Rica brindó un amplio espacio a dicho acontecimiento, como un homenaje al "valiente pueblo mexicano, el centinela de nuestra vida autónoma, que se agita laboriosamente, asombrando al mundo con su industria y su actitud caballeresca”. ${ }^{37}$ Consideraba que la visita de la Delegación Comercial Mexicana había sido una revelación, como la más sobresaliente del Gobierno de México, pues, marcaba la posibilidad de la liberación de los pueblos centroamericanos de la dependencia comercial a la que estaban sometidos, y abría nuevos caminos para poder obtener artículos y mercados para la venta de sus productos.

34 Anexo. Informe rendido ayer por el Sr. Presidente de la República a la representación nacional, 2 de septiembre de 1923.

$35 \quad$ Diario de Costa Rica, 24 de junio de 1923, 2.

36 San José, agosto 9 de 1938, Expediente III-171-4, AHSREM.

37 El Diario de Costa Rica, 8 de junio, 1920, 4- 5. 
La visita incluyó diversas exhibiciones cinematográficas mexicanas "al través de las cuales admiramos los valores monumentales, las bellezas arqueológicas que atestiguan un pasado de grandeza y hasta la vida social de México, en las revistas militares y los festejos cívicos”. ${ }^{38}$ Por otro lado, la exhibición de productos mexicanos (textiles, artesanías y dulces) también era importante porque marcó el inicio de la política cultural indigenista.

Inicialmente, esta actividad se realizó en México para mostrar la fuerza cultural de la nación después de la Revolución, con la finalidad de recuperar y valorar lo que antes se negaba como parte de la redefinición de la identidad nacional. Entonces, lo que México exportaba no sólo era su antimperialismo sino también su riqueza económica y, sobre todo, cultural.

El presidente de Costa Rica, al dar la bienvenida al encargado de la delegación mexicana, Angel Lagarde, expresó su deseo porque se estrecharan los lazos entre ambos pueblos: "el suyo tan rico y poderoso y el nuestro tan pequeño y ansioso de grandeza”. ${ }^{39}$ Así se expresaba el deseo, por lo menos en el discurso, de unirse al camino propuesto por México.

Al respecto, el cronista de El Diario de Costa Rica decía que "México es nuestro hermano mayor y allí debemos volver los ojos”. Así se sugiere que Costa Rica debería abrirle un buen mercado a los productos, para que los demás países pudieran apreciar lo que vale México, “el centinela en el avance y la conservación de la gallardía de la raza azteca”. ${ }^{40}$

Por su parte, satirizando y refiriéndose a la lógica de la política estadounidense del “big stick” y de la diplomacia del dólar, con relación a la política mexicana, Carleton Beals, periodista norteamericano, dijo en 1926: "Mexico is marching on the canal with music, banners, and flowers. We are marching with machine guns, dollars, and Marines." ${ }^{41}$ Los resultados de ambas políticas fueron distintos: los norteamericanos controlaron la economía y la política de la región; los mexicanos afianzaron su influencia cultural.

En el afán político mexicano por mostrarse como una nación de avanzada, con garantías individuales reconocidas a partir del triunfo de la revolución, se propuso el intercambio de ciudadanía entre todas las naciones latinoamericanas. Fue Higinio Alvarez quien presentó en el Senado de México el 22 de septiembre de 1927, la propuesta abogando por la ciudadanía continental que garantizaría los mismos derechos a todos los latinoamericanos. Por ejemplo, $38 \quad$ Ibid.

$39 \quad$ El Diario de Costa Rica, San José, 24 de mayo 24, 1920.

$40 \quad$ Diario de Costa Rica, San José, 7 de mayo, 1920.

41 Jürgen Bouchenau, In the Shadow of the giant. The making of Mexico's Central America policy. 1876-

1930, (The University of Alabama Press, 1996), 142. 
libre movilidad sin pasaporte en cualquier país del continente. Tal medida, debía consignarse en las constituciones "concediendo a los latinoamericanos visitantes las mismas prerrogativas que a los nacionales, estando México dispuesto a hacer lo mismo tan pronto como expresando su deseo de corresponder a la mayoría de las naciones latinoamericanas”. ${ }^{42}$

Con este propósito México envió una comisión para que recorriera los países de América Latina para promover su aceptación. Aunque esta propuesta tuvo difusión no prosperó debido a que los nacionalismos eran más fuertes que la supuesta integración hispanoamericana.

\section{Juan de Dios Bojórquez: entre la diplomacia y la difusión cultural}

En el ámbito centroamericano fue Juan de Dios Bojórquez quien canalizó todas sus energías tras la búsqueda del acercamiento con Guatemala y con el resto de los países de la región. En 1921, fue nombrado Ministro Residente de México ante Honduras y delegado de la Universidad Nacional de México en Centroamérica. Un año después, lo designaron Enviado Extraordinario y Ministro Plenipotenciario en Guatemala. Vasconcelos, conocedor de su labor, lo llamaba "Diputado por Centro América." ${ }^{3}$

Cosío Villegas en sus Memorias menciona que en 1924 fue por primera vez a Guatemala como delegado estudiantil, cuando Bojórquez se desempeñaba como ministro. Lo primero que hizo fue interesarse en el destacado trabajo que el diplomático desempeñaba como parte de la política mexicana de acercamiento y por iniciativa propia. Según Cosío, Bojórquez hacía dos viajes anuales a México y volvía a Guatemala llevando algún espectáculo: una exposición de pintura, un equipo de futbol, algún pequeño grupo teatral, recitadores, cantantes y bailarines. Cuando los gastos no eran costeados por Relaciones Exteriores, el ministro acudía al general Francisco Serrano y al coronel Celis. Este último agregado militar de la Legación de México en Guatemala. ${ }^{44}$

Bojórquez estuvo vinculado a las primeras estaciones receptoras de radio existentes en Guatemala, regalo del gobierno mexicano y a la formación de la Agencia Trens, que empezó a enviar noticias de México a los cinco países centroamericanos con la finalidad de "borrar muchos prejuicios” ${ }^{\$ 5}$. Para adelantarse a la crítica que las estaciones servían para hacer propaganda de México, las estaciones fueron transformadas en transmisoras. Así las noticias de un país llegaban $42 \quad$ El Diario de Costa Rica, 3 de enero de 1928.

43 Bojórquez Juan de Dios- Su expediente. Clasificación Topográfica 1-131-333, Legajo I, AHSREM.

44 Daniel Cosío Villegas, Memorias, (México: Joaquín Mortiz, SEP, 1986), 105.

$45 \quad$ El Heraldo (México), "Huéspedes de honor son los periodistas al próximo congreso. Atendiendo a la invitación que se les hizo por medio de la Agencia Mexicana Trens”, 24 de agosto de 1923, 1. 
a los otros y, además, a México, en donde se recogían en boletines especiales, que eran impresos para ser enviados a los círculos oficiales, bibliotecas públicas y la prensa.

Mencionemos también que las primeras bibliotecas modernas fueron obsequio del gobierno mexicano. Bojórquez instaló la Biblioteca México en Guatemala, primero en la casa que ocupaba la legación y, posteriormente, en un edificio acondicionado especialmente para eso.

Bojórquez nombró a Rafael Arévalo Martínez, considerado entonces como el primer escritor guatemalteco, director de la primera Biblioteca México (1924). Su contacto con Bojórquez, el "gran apóstol de la propaganda antiyanqui en Centroamérica", como lo nombraba el embajador francés en Guatemala, influyó para que escribiera la novela La oficina de paz Orolandia. Esta fue dedicada a Bojórquez y a México: "mi deuda con su patria, anterior a la que he contraído con usted, no es menos grande.” En esta novela el autor criticaba la presencia abarcadora del imperialismo norteamericano, por ello la novela se subtitulaba "Novela de imperialismo yanqui”. Abordaba abiertamente los efectos negativos del régimen concesionario en toda Centroamérica y los poderes excesivos de la UFCO y la IRCA, al respecto señalaba: "Fletes prohibitivos en ferrocarriles y naves yanquis; y la posesión nominal de la tierra para el orolandés, porque los frutos de la tierra, la leche y la miel cananitas, son para los amos del planeta." ${ }^{46}$

Además de su crítica al imperialismo, reconocía el liderazgo intelectual de Vasconcelos. En la voz del personaje principal, Buendía, decía: "Lea "La antorcha”, que el pensador mexicano ha hecho flamear sobre su mundo, con el mote vasconcélico, jay tan iluminado! "por mi raza hablara el espíritu”, su prédica mejor pide esto: higiene”. ${ }^{47}$

El campo de acción de Bojórquez trascendió la relación con los intelectuales. En 1922, siendo Ministro Plenipotenciario, destacaba, en una carta dirigida a J. Pani, Secretario de Relaciones Exteriores de México, las misiones que desempeñaba en Guatemala y en Centroamérica. La misiva tenía como objetivo principal presentar la renuncia al cargo que venía desempeñando debido a la falta de apoyo de esa Secretaría. El ministro protestaba porque Pani no había respetado su nombramiento como delegado de la Universidad Nacional (éste le había 46 Rafael Arévalo Martínez, La oficina de paz Orolandia, (Tipografía Sánchez \& De Guise: Guatemala, 1925) 157. Véase también el trabajo de Arturo Taracena Arriola, “Arévalo Martínez y la Guatemala de los años diez”, en Dante Liano (Coord.), Rafael Arévalo Martínez. El hombre que parecía un caballo y otros cuentos, (Madrid: Colección Archivos, ALLCA XX/CNCA, 1997).

47 Ibíd., 121. 
sido concedido por Vasconcelos, entonces rector de la Universidad, y corroborado por Obregón). Dicho nombramiento tenía como objetivo lograr un mayor acercamiento entre estudiantes mexicanos y centroamericanos y fundar, en los cinco países del Istmo, bibliotecas populares. Sin embargo, para el envío de becarios, se desautorizaron sus atribuciones de delegado universitario, poniéndolo en mal predicamento ante las legaciones de México en Costa Rica y Nicaragua. Bojórquez consideraba que el gobierno mexicano cometía un error al ordenar que las becas se concedieran por conducto de los gobiernos, porque en "en vez de beneficiar a una nación, convierte el valioso obsequio en botín político, que el gobierno de El Salvador y Nicaragua emplearán para comprometer a sus enemigos, o fortalecer alianzas con morbosos elementos de sus carcomidas administraciones." ${ }^{\text {48 }}$

Después de expresar su descontento, Bojórquez detallaba las actividades desempeñadas en Guatemala y Centroamérica. Lo señalado por el ministro nos muestra el funcionamiento de la triada para la región: Obregón-Vasconcelos-Bojórquez, por lo menos para los primeros años de la década de los veinte, periodo en que fue más evidente la política mexicana de acercamiento hacia Centroamérica. La asignación de becas a Centroamericanos era uno de los elementos centrales de dicha política. Bojórquez consideraba que por medio de los estudiantes, se conseguiría mayor acercamiento con los pueblos centroamericanos y que algunos profesionistas "eran tan mexicanos como nosotros” y hacían la mejor propaganda de México en el extranjero. Esta idea agradó a Obregón, quien sugirió que se otorgaran 60 becas para estudiantes de Centroamérica, doce por cada país. La indicación se trasladó a Vasconcelos para que oficializara el acuerdo (éste se firmó el 19 de octubre de 1921) y Bojórquez se encargó, en calidad de delegado de la Universidad, de dar la noticia en el Istmo. ${ }^{49}$

Además, Vasconcelos le autorizó la designación de los becarios. Sin embargo, el ministro prefirió no asumir toda la responsabilidad. Por eso giró una circular con datos para los representantes en Guatemala, El Salvador, Nicaragua y Costa Rica. En Tegucigalpa formó un comité presidido por el Ministro de Instrucción para proceder a la selección equitativa y públicamente.

Según Bojórquez, nunca pretendió abarcarlo todo en Centroamérica, aunque pudiera parecer que así fue. Por eso pretendía contar con los Ministros o Encargados de Legaciones $48 \quad$ Juan de Dios Bojórquez. Su expediente personal, AHSREM.

$49 \quad$ El 17 de noviembre de 1921, la Secretaría de Guerra anunció que concedía quince becas para el Colegio Militar y cinco para la Escuela de Aviación. Juan de Dios Bojórquez - Su expediente personal, AHSREM. 
de México y con los Ministros de Instrucción o con profesores distinguidos que garantizaran la buena distribución de las becas. Por ejemplo, en Costa Rica, contó con la ayuda del ex ministro de Instrucción Carlos García Monge. Sin embargo, el plan diseñado por Bojórquez no recibió el apoyo del representante mexicano en El Salvador, J. M. Ferrer, quien, según sus palabras, se preocupaba más por defender al gobierno salvadoreño que por trabajar a favor de México:

No contando con la opinión de los estudiantes, entre quienes están sus más terribles enemigos, el gobierno salvadoreño se valió de la amistad que liga al Dr. Juan Francisco Paredes, bi-Ministro de Relaciones e Instrucción Pública, con el señor Ferrer, para insinuar a México que las becas se dieran por conducto de los gobiernos. Sería un fracaso la elección en esta forma, porque, ¿quién no sabe que en Centro-América todos los pasos de los gobiernos son presididos por los compromisos políticos? Irán entonces sobre todo El Salvador y de Nicaragua, favoritos, de las administraciones públicas, lo cual trataba de evitar yo, de acuerdo con las instrucciones recibidas del Lic. Vasconcelos. ${ }^{50}$

El ministro alegaba a su favor el hecho de ser quien más conocimiento tenía de las cinco secciones de Centro América. Su renuncia no fue aceptada y en su correspondencia diplomática no volvió a mencionar el asunto. Bojórquez consideraba que el otorgamiento de becas había sido recibido favorablemente. De Honduras, con el agrado y el aplauso del pueblo hondureño, pronto partirían de Amapala hacia la capital de México once becarios de la Secretaría de Educación Pública (uno de ellos ya se encontraba allá) y cuatro pensionados por la Secretaría de Guerra. El escritor hondureño Rafael Heliodoro Valle le escribía para agradecerle el empeño puesto en el asunto. ${ }^{51}$

Además de preocuparse por la buena distribución de las becas, el mexicano realizaba giras por los países centroamericanos. Por ejemplo, en 1923, viajó de Guatemala a Honduras, junto con Miguel Ángel Asturias, para visitar algunos diarios y dictar conferencias sobre la

$50 \quad$ Ibíd.

51 Carta de Valle dirigida a Bojórquez, México, 8 de marzo, 1922. Expediente de Juan de Dios Bojórquez, Fondo Reservado Rafael Heliodoro Valle (FRHV), Biblioteca Nacional de México. 
Universidad Popular (otro de los grandes proyectos impulsados por Vasconcelos). En una editorial del periódico hondureño Excelsior fue calificado como "protector del obrerismo hondureño". ${ }^{22}$

Agreguemos que su labor no se limitó a la difusión cultural, sino también al análisis y participación en asuntos políticos. En una correspondencia enviada desde Guatemala a la Secretaría de Relaciones Exteriores de México, el 23 de mayo de 1923, el ministro señalaba que Honduras era "la tierra que más se parece a nosotros y mejor nos comprende". Por tal razón, México, con toda la discreción del caso, debería trabajar en la fusión del Partido Liberal, para evitar el triunfo de los conservadores:

Creo que los representantes de México en Centro América, debemos trabajar con toda la discreción del caso, porque los dichosos pactos [de Washington] no pasen en estas asambleas. Tengo la impresión que censuran a un periodista venezolano quien afirmó que, con la ratificación, se llegaría a conseguir la "chamorrización de Centro América". ${ }^{53}$

En respuesta a la misiva, la Secretaría de Relaciones Exteriores de México, envía un memorandum al ministro, indicándole que trabaje preferentemente en la fusión de los elementos liberales. Así se podría evitar la división, mediante la presentación de un candidato de transición que permitiera al Partido Liberal presentar un solo candidato frente al conservador. Los informes enviados desde Centroamérica indicaban que la intervención entre los elementos liberales tendría buena aceptación, siempre y cuando se hiciera con discreción para evitar que las gestiones se interpretaran como intromisión en los asuntos interiores de otro país. ${ }^{54}$

En el ámbito periodístico e intelectual la labor desempeñada por Bojórquez fue asimismo apreciada. Por ejemplo, el periodista Hernán Robleto consideraba en un artículo titulado "Los periodistas diplomáticos”, que éste hizo en poco tiempo más labor que todas las delegaciones que México ha mantenido en sus vecinos del Sur:

52 Excelsior, Tegucigalpa, 9 de mayo, 1923. Anexo, Bojórquez Juan de Dios- Su expediente. Clasificación Topográfica 1-17-24. Legajo II, Años-1923-1924, AHSREM.

53 Carta de Juan de Dios Bojórquez, México, 8 de agosto de 1923. Bojórquez Juan de Dios- Su expediente. Clasificación Topográfica 1-17-24, Legajo II, Años-1923-1924, AHSREM.

54 Ibíd. 
[...] ha encausado, sin mucho protocolo, sin mucho discurso de ocasión, una enorme corriente de simpatía hacia esta su tierra tan buscada y querida por los centroamericanos; ha hecho avanzar a México más allá del Suchiate, entrándosenos, no con tropas invasoras ni conquistadoras concesiones capitalistas, ni pactos internacionales, sino con la efectiva y duradera arma de los sentimientos francos, de su mano abnegada y fuerte que cruzan las venas de una sangre común. ${ }^{55}$

Para Robleto, Bojórquez, "El simpático muchacho socialista”, tenía la ventaja de ser periodista. Esto le permitía sondear "las muchedumbres", de indagar sobre las necesidades y aspiraciones colectivas, por eso podía desempeñar mejor los cargos diplomáticos.

La política implementada por Bojórquez era para Robleto un ejemplo para Centroamérica. Por esto proponía la creación de una biblioteca centroamericana, al estilo de la Biblioteca México existente en Guatemala, que propiciara el conocimiento de la realidad centroamericana. Además, se debían fomentar las visitas de profesionales, de hombres de negocios, de artistas y de atletas.

Elministro fomentaba las relaciones comerciales e intelectuales entre México y Guatemala. En 1923 organizó un viaje a su país acompañado del subsecretario guatemalteco de Fomento, Ricardo H. Peralta, y del redactor del periódico El Imparcial y miembro de la junta directiva de la Universidad Popular, David Vela. En el aspecto comercial pretendió realizar gestiones que favorecieran las exportaciones de ganado guatemalteco a México, para esto el subsecretario se entrevistó con el presidente Obregón. Las gestiones posiblemente fructificaron porque en esos años México, después de diez años de revolución, necesitaba importar artículos de primera necesidad, como ganado vacuno y porcino, azúcar, maíz, arroz, trigo, manteca y otros artículos de primera necesidad. ${ }^{56}$

Por su parte, David Vela llevaba la misión de saludar, a nombre de las Universidades Nacional y Popular de Guatemala, al presidente, a Vasconcelos, secretario de educación y a Antonio Caso, rector de la Universidad Nacional de México.

Además, Bojórquez gestionaba la disminución de horas de viaje México-Suchiate a partir del mejoramiento de las vías de comunicación, lo que favorecería el turismo y los negocios. Las

55 El imparcial, “Crónicas de México. Los periodistas diplomáticos”, en El imparcial, 18 de octubre de 1924, 5.

56 Cfr. Luis G. Zorrilla, Relaciones de México con la República de Centroamérica y con Guatemala, (México: Porrúa, 1984). 
actividades fomentadas por éste eran consideradas como la "forma práctica en que se significan las relaciones de México con Guatemala”. Días después del regreso de la delegación, se anunció la llegada del poeta Alfonso Cravioto, como representante de la SEP, a iniciativa de la invitación que Porfirio Barba Jacob, uno de los fundadores de la Universidad Popular, había hecho a Vasconcelos a nombre de ésta.

También se anunció que la Secretaría de Educación de México invitaba al músico Jesús Castillo, considerado el mejor representante de la música guatemalteca, para que diera a conocer su obra en los grandes centros musicales y en las fiestas del pueblo. Además, se organizó una visita de deportistas guatemaltecos al país vecino, correspondiendo a la que hicieran deportistas mexicanos a Guatemala. ${ }^{57}$ En México, siguiendo instrucciones de la SEP, según un programa trazado desde 1921 por Vasconcelos "para la educación de las masas humildes y la exaltación del sentimiento patrio de la raza”, se efectuó en Chapultepec un festival dando a conocer la música, los cantos, los bailes, las telas y los trajes típicos.

El arduo trabajo desarrollado por Bojórquez tuvo resultados positivos. Es claro que despertó en una parte del sector intelectual guatemalteco admiración por los cambios surgidos de la Revolución Mexicana y por la política cultural difundida en la región a partir de diversos mecanismos que vincularon lo cultural, lo político y comercial. Baste decir que los redactores y colaboradores de El Imparcial, eran conocidos como los “mexicanistas". Una de las opiniones vertidas en ese diario con relación a la política cultural mexicana decía:

Como se sabe, esos festivales, organizados durante la gran cruzada educadora del vecino país, se dan hoy en todas las ciudades y los pueblos de México: son gratuitas y se inspiran siempre en el sentimiento y las necesidades del pueblo. Al efectuar el que se dedicará a Guatemala, se pretende que los obreros mexicanos vean las grandes semejanzas que hay entre los dos pueblos y, por consiguiente las razones morales que existen para que trabajen por el progreso del mundo dentro de una amistad más estrecha, leal, activa y fecunda..$^{58}$

57 El imparcial, “La jira de los viajeros guatemaltecos en la ciudad de México”, El imparcial, Guatemala, 23 de julio de 1923, 1; "Regreso del excelentísimo señor ministro de México. Sus gestiones a favor de nuestros exportadores de ganado a su país", 4 de agosto de 1923, 1.

58 "La forma práctica en que significa la amistad de México con Guatemala", en El Imparcial, 22 de agosto de 1923, p. 1. 
Aunque Bojórquez ocupó un lugar central en el diseño y aplicación de la estrategia mexicana hacia Centroamérica en los años veinte, hasta ahora ha sido poco estudiado. A partir de él es posible rastrear a mayor profundidad el impacto mexicano en la región en los años de nuestro estudio. Además, es una muestra clara de la relación entre la diplomacia y la difusión cultural como estrategia vinculada a la política exterior mexicana de esos años.

\section{Conclusiones}

La revisión que hemos realizado en este trabajo nos permite establecer que en los años veinte las relaciones culturales y políticas de México y Centroamérica se intensificaron. El primero, impulsó una política que, por lo menos en los años iniciales de la década, fomentó el acercamiento con el istmo. Los ideales de una generación coincidieron con los planteamientos de la revolución mexicana de 1910, motivando así la participación en su defensa y difusión. Sin embargo, la estrategia mexicana no fue suficiente para borrar la desconfianza histórica (sobre todo de Guatemala) construida a raíz de la independencia y la formación de los estados nacionales

La política exterior mexicana de los años veinte hacia Centroamérica incluyó diversos mecanismos de propaganda y difusión que involucraron elementos culturales, diplomáticos, políticos y económicos. Los intelectuales desempeñaron un papel determinante en el diseño y ejecución de dicha política. Vasconcelos y Juan de Dios Bojórquez, apoyados por Obregón, propiciaron el acercamiento con los países centroamericanos. De esta manera se haría frente a la fuerte presencia norteamericana en la región a partir de la difusión de la imagen de México como un país de avanzada, como el "hermano mayor de Centroamérica". A finales de la década de los veinte se iniciará el viraje hacia la institucionalización de la revolución, por lo tanto, la apertura política se hará cada vez más estrecha. 